\title{
Genetic assessment reveals inbreeding, possible hybridization and low levels of genetic structure in a declining goose population
}

\author{
Johanna Honka ${ }^{1}$, Serena Baini ${ }^{2}$, Jeremy Searle ${ }^{3}$, Laura Kvist ${ }^{1}$, and Jouni Aspi ${ }^{1}$ \\ ${ }^{1}$ University of Oulu \\ ${ }^{2}$ University of Rome Tor Vergata \\ ${ }^{3}$ Cornell University
}

August 18, 2021

\begin{abstract}
The population numbers of taiga bean goose (Anser fabalis fabalis) have halved during recent decades. Since this subspecies is hunted throughout most of its range, the decline is of management concern. Knowledge of the genetic population structure and diversity is important for guiding management and conservation efforts. Genetically unique subpopulations might be hunted to extinction if not managed separately, and any inbreeding depression or lack of genetic diversity may affect the ability to adapt to changing environments and increase the extinction risk. We used microsatellite and mitochondrial DNA markers to study the genetic population structure and diversity among taiga bean geese breeding within the Central flyway management unit using non-invasively collected feathers. We found some genetic structuring with the maternally inherited mitochondrial DNA between four geographic regions $\left(F_{\mathrm{ST}}=0.11-0.20\right)$ but none with the nuclear microsatellite markers (all pairwise $F_{\mathrm{ST}}$-values $0.002-$ 0.005). These results could be explained by female natal philopatry and male-biased dispersal, which completely homogenizes the nuclear genome. Therefore, the population could be managed as a single unit. Genetic diversity was still at a moderate level (average $H_{\mathrm{E}}=0.69$ ) and there were no signs of past population size reductions, although significantly positive inbreeding coefficients in all sampling sites $\left(F_{\text {IS }}=0.05-0.10\right)$ and high relatedness values $(r=0.60-0.86)$ between some individuals could indicate inbreeding. In addition, there was evidence of either incomplete lineage sorting or introgression from the pink-footed goose (A. brachyrhynchus). The current population is not under threat by genetic impoverishment but monitoring in the future is desirable.
\end{abstract}

\section{Hosted file}

Honka et al. 2021 manuscript.docx available at https://authorea.com/users/430875/articles/ 534396-genetic-assessment-reveals-inbreeding-possible-hybridization-and-low-levels-ofgenetic-structure-in-a-declining-goose-population 
figures/Fig1/Fig1-eps-converted-to.pdf 
figures/Fig2/Fig2-eps-converted-to.pdf 
figures/Fig3/Fig3-eps-converted-to.pdf 
figures/Fig4/Fig4-eps-converted-to.pdf 
figures/Fig5/Fig5-eps-converted-to.pdf 
figures/Fig6/Fig6-eps-converted-to.pdf 
figures/Fig7/Fig7-eps-converted-to.pdf 
figures/Fig8/Fig8-eps-converted-to.pdf 


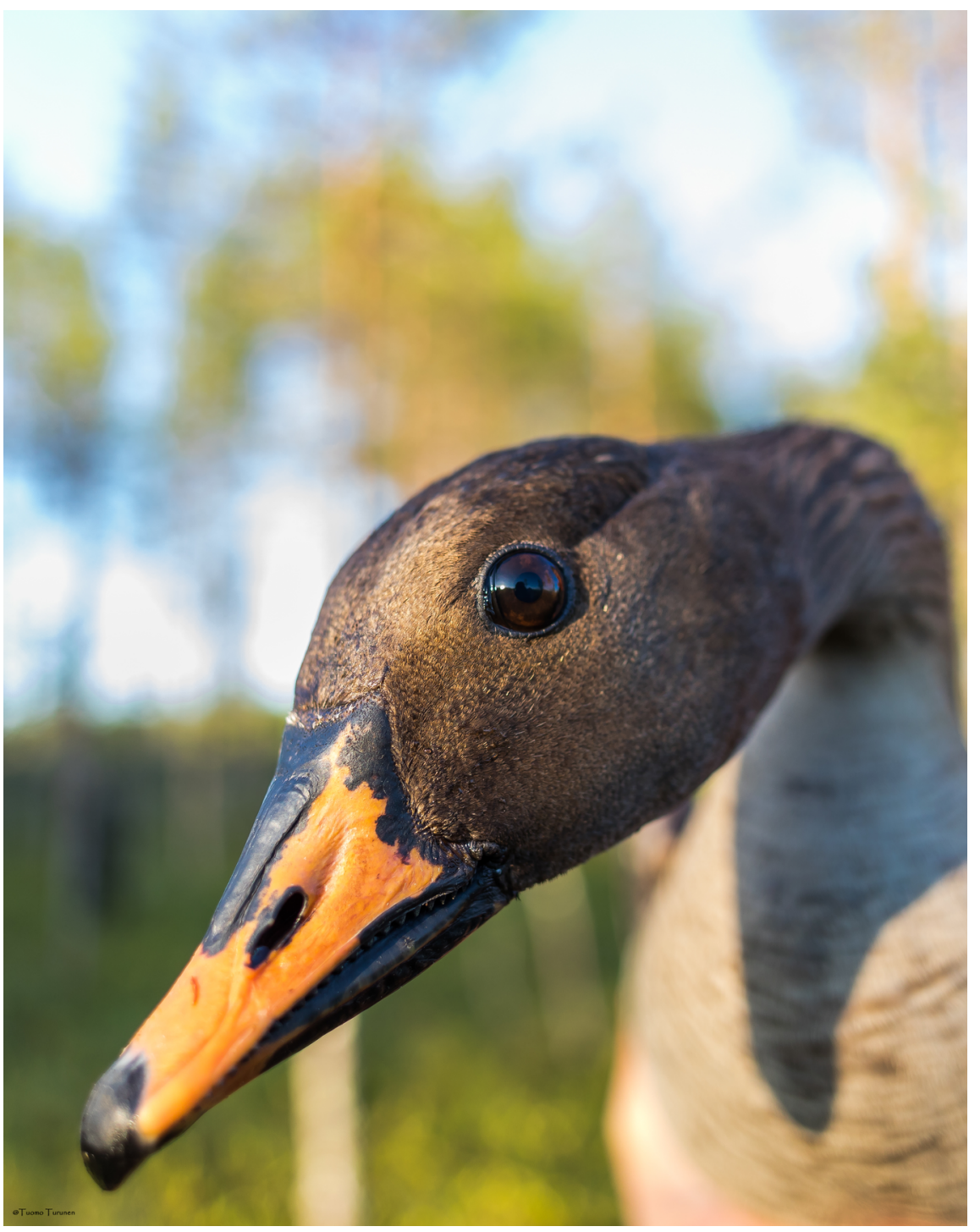

